\section{Accelerated Healing Period with Hydrophilic Implant Placed in Sheep Tibia}

Suelen Cristina Sartoretto ${ }^{1}$, José de Albuquerque Calasans-Maia ${ }^{2}$, Yanan Osório da Costa $^{3}$, Rafael Seabra Louro ${ }^{1}$, José Mauro Granjeiro ${ }^{3,4}$, Mônica Diuana Calasans-Maia ${ }^{1}$

The objective of this study was to evaluate the early osseointegration of two different implants surfaces, a sandblasted and acid-etched surface (TN) compared with same geometry and surface roughness modified to be hydrophilic/wettable by conditioning in an isotonic solution of $0.9 \%$ sodium-chloride (TA) through histological and histomorphometric analysis after sheep tibia implantation. Forty dental implants, divided in two groups (TN and TA) were placed in the left tibia of twenty healthy, skeletally mature Santa Ines sheep ( $n=5$ /experimental period). After 7, 14, 21 and 28 days post-implantation, the samples were removed and the sheep were kept alive. Analysis of resin sections ( $30 \mu \mathrm{m})$ allowed the quantification of bone area (BA) and bone-to-implant contact (BIC). TA group presented nearly 50\% increase in BA at 14 days ( $p<0.001$, ANOVA - Tukey's post test) compared with 7 days. The TA presented higher values than the TN for BA and BIC at 14, 21, and 28 days after placement, stabilizing bone healing. TA hydrophilic surface promoted early osseointegration at 14 and 21 days compared to TN, accelerating bone healing period post-implant placement in sheep tibia.
'Department of Oral Surgery, UFF - Universidade Federal Fluminense, Niterói, RJ, Brazil ${ }^{2}$ Department of Orthodontics, UFF - Universidade Federal Fluminense, Nova Friburgo, RJ, Brazil ${ }^{3}$ Dental School, UFF - Universidade Federal Fluminense, Niterói, RJ, Brazil ${ }^{4}$ Division of Quality and Technology, INMETRO - Instituto Nacional de Metrologia, Qualidade e Tecnologia, Duque de Caxias, RJ, Brazil

Correspondence: José Mauro Granjeiro, Rua Mário Santos Braga, 28, $3^{\circ}$ andar, Centro, 24020-140 Niterói, RJ, Brasil. Tel: +55-21-2629-9803. e-mail: jmgranjeiro@gmail.com

Key Words: dental implant hydrophilic surface, osseointegration, bone healing, histomorphometric evaluation.

\section{Introduction}

The constant search for improvements in modern implant dentistry has transcended the implant shape. Modifications on the implant surface either topographically (such as roughness) or chemically aim to accelerate the osseointegration contributing to the success of oral rehabilitation.

Since the beginning of implant dentistry studies, particular importance has been placed on the design of implant surfaces, which is one of six factors that are particularly important for implant osseointegration $(1,2)$. Hydrophilic implant surfaces account for faster wettability, favoring cell-implant contact, the initial phases of wound healing and a cascade of events leading to the osteogenesis (3). At the end, bone apposition increase bone-implant contact (BIC) (4) and improve bonding strength during the early stages of bone repair $(5,6)$.

Recently, in vitro data demonstrated the potential benefit of hydrophilic surfaces in improving the differentiation of human mesenchymal stromal cells and osteoblasts, favoring the induction of early matrix mineralization $(7,8)$. Moreover, when in contact with whole blood, a hydrophilic surface increases contact activation of the coagulation cascade. In other words, implant hydrophilic surface possess thrombogenic properties and improve bone healing (9).
Furthermore, this surface causes down-regulation of proinflammatory cytokine gene expression in monocytes, modulating the inflammatory response (10).

The literature presents favorable outcomes of hydrophilic surface regarding the osseointegration due to its advantage during early wound healing. In vivo evaluation have presented increase of bone-to-implant contact (BIC) in studies using mini-pigs model (6), dogs (11) and rats (12).

In a clinical study, a hydrophilic surface had a proosteogenic and pro-angiogenic effect on gene expression, increasing osteogenesis (13).

In this analysis, both implants tested are commercially available; however, regulators and professionals must have evidence that demonstrate the safety and efficacy of these products based on standardized protocols in order to reduce the use of inefficient products $(6,14)$.

Ovine are medium size animals suitable for medical research, due to availability, and acceptance by the animal research society. In the recent years, the use of this animal model has increased, mainly because of their similarity to humans in bone regeneration, the weight and structure of bone and articular tissues $(15,16)$.

In order to better address this issue, here we conducted a histomorphometric analysis of early osseointegration (BA and $\mathrm{BIC}$ ) on two different implants surfaces, a sand- 
blasted and acid-etched surface (TN) compared with same geometry and surface roughness modified to be hydrophilic/ wettability by conditioning in an isotonic solution of $0.9 \%$ sodium-chloride (TA).

\section{Material and Methods}

\section{Animal Model}

Twenty adult female Santa Ines sheep, weight $45 \pm 3$ $\mathrm{kg}$, and age $8 \pm 1$ years were used. All animals were in good health conditions and were vaccinated against diseases pre-operatively and were screened to ensure good physical conditions (claws and worms). The animals were kept in individual cages and received water and mineral salt ad libitum throughout the study. The supervision of animal care, diet and pre and post-operative fasting were conducted by a veterinary responsible for the sheep of Farm School of UFF - Universidade Federal Fluminense.

Animal experiments and breeding were performed under conditions approved by the Institutional Review Board (CEP/UFF: 552/2013), in compliance with the NIH Guide for Care and Use of Laboratory Animals and with Brazilian legislation on animal use. This study is reported according to the ARRIVE guidelines (Animal Research: Reporting of In Vivo Experiments), in regard relevant items (17). The sheep model was chosen in compliance with the guidelines of 3Rs Program (Reduction, Refinement, Replacement) that aim reducing the number of animals during experimentation and minimizes pain and discomfort.

\section{Implants}

Two groups of titanium (Ti) dental implants with different surfaces were studied: Titamax NeoPoros (TN), lot 800.136.215, and Titamax Acqua (TA), lot 800.136.216, which are both Morse taper junctions (CM Titamax; Neodent, Curitiba, PR, Brazil).

TN group: The implant surface was created by the sand-blasting and acid-etching processes.

TA group: The implant surface was created by the sandblasting and acid-etching processes and was chemically modified by conditioning with an isotonic solution of $0.9 \%$ sodium chloride.

\section{In Vivo Procedures \\ Materials}

A total of 40 manufactured Ti dental implants, $3.5 \mathrm{~mm}$ in diameter and $7.0 \mathrm{~mm}$ long, were divided into two groups according to surface treatment: TN and TA ( $n=20$ per group).

\section{Surgical Procedure}

Before surgery, food and water were withheld for $24 \mathrm{~h}$. All procedures that could result in anxiety and/or pain for the animals were conducted under anesthesia. The animals were operated on under general anesthesia and received inhalation anesthesia premedication with acepromazine (0.05 mg/kg/i.v., Acepran ${ }^{\circledR}$; Vetnil, Louveira, SP, Brazil), diazepam $\left(0.2 \mathrm{mg} / \mathrm{kg} / \mathrm{i} . \mathrm{v}_{\text {., }}\right.$ diazepam; Teuto, Anápolis, G0, Brazil) and morphine (0.4 mg/kg/i.m., Dimorf ${ }^{\circledR}$; Cristália, Itapira, SP, Brazil). After 20 min, when the animals were visibly sedated and exhibited no responses to pain, cephalic vein cannulation was performed and lactated Ringer's solution ( $5 \mathrm{ml} / \mathrm{kg} / \mathrm{h} /$ i.v.; Baxter Hospitalar Ltda, São Paulo, $\mathrm{SP}, \mathrm{Brazil})$ was infused. Anesthesia was then induced with propofol (4 mg/kg/i.v., Diprivan ${ }^{\circledR}$; Astra Zeneca, Cotia, SP, Brazil). The animals were intubated (orotracheal intubation), and the general anesthesia was maintained by inhalation of $1 \%$ isoflurane (Isoforine ${ }^{\circledR}$; Cristália). After the start of anesthesia, lidocaine ( $4 \mathrm{mg} / \mathrm{kg}$, Xylestesin ${ }^{\circledR} ;$ Cristália) and morphine $\left(0.1 \mathrm{mg} / \mathrm{kg}\right.$, Dimorf ${ }^{\circledR}$; Cristália) were used for epidural block. The anesthetic procedures were performed under veterinary supervision.

For surgical procedures, all surgical areas were clipped, prepared and draped using a sterile technique. Following the trichotomy, the disinfection of both tibial regions was performed with a $0.2 \%$ chlorhexidine solution (Riohex Scrub ${ }^{\circledR} ;$ Rioquimica, São José do Rio Preto, SP, Brazil).

\section{Implant Installation}

Two 1-cm incisions were performed in the epithelium of right sheep' tibia of each animal, followed by periosteal detachment and bone exposure. Each site was perforated within a 2-cm distance of the other. Under constant irrigation with $0.9 \%$ sodium saline solution, the perforations were performed with a surgical drill according to the manufacturer's surgical protocol. All drilling procedures were conducted at $1200 \mathrm{rpm}$. One implant per group was installed in the proximal site of right tibia at $24 \mathrm{rpm}$, and the final insertion torque was determined to be $50 \mathrm{Ncm}^{2}$. The periosteum around the bone perforations was placed back in position and attached to the subcutaneous tissue using an interrupted suture.

\section{Postoperative Care}

Post-operative pain and inflammation were controlled with the administration of tramadol ( $4 \mathrm{mg} / \mathrm{kg} /$ i.v., Tramal $^{\circledR}$; Pfizer, São Paulo, SP, Brazil) and meloxicam (0.5/kg/oral, Meloxivet ${ }^{\circledR}$; Duprat, Rio de Janeiro, RJ, Brazil) for 3 days. During the first post-operative week, antibiotic prophylaxis was administered using oxytetracycline $(0.1 \mathrm{mg} / \mathrm{kg} / \mathrm{i} . \mathrm{m}$., Terramicina ${ }^{\circledR}$; Pfizer). Silver spray was topically applied daily to prevent local infection. After the surgery, the animals received diet and had free access to drinking water.

\section{Histologic Specimens Preparation and Maintenance of Animals Alive}


The animals were submitted to anaesthetic procedures as described before. The samples were collected from five animals for each experimental period $(7,14,21$ and 28 days). The animals were maintained alive after biopsy. The tissue blocks carrying the implants were removed with trephines of $4 \mathrm{~mm}$ in diameter and were fixed in $4 \%$ buffered formaldehyde. The blocks were dehydrated in ascending grades of alcohol and infiltrated through daily changes of ascending grades of resin (Technovit 7200 VLC, Kultzer \& Co., Wehrheim, Germany). Finally, the samples were embedded in the same resin. Using a cutting-grinding unit and a micro-grinding system (Exakt ${ }^{\circledR}$, Apparatebau, Norderstedt, Germany), the blocks were cut in the mesio-distal plane, and two central sections were obtained. All sections were reduced to a final thickness of approximately $30 \mu \mathrm{m}$ and stained in toluidine blue. Using this staining, old bone exhibited a light purple color and was easily distinguishable from new bone (formed during regeneration), which exhibited a darker purple color. The slices were examined with a light microscope (Olympus BX43, Tokyo, Japan) and image acquisition software (CellSens ${ }^{\circledR} 1.9$ Digital, Tokyo, Japan).

\section{Histomorphometric Analysis}

Eight non-superimposed fields corresponding to the implant/bone interface were captured by scanning each histologic slice at $\times 20$ magnification.

The region of interest (ROI) was defined as the area parallel to the outer implant contour and between the threads, and two quantitative parameters were evaluated using digital image analysis software (Image ${ }^{\circledR}$ v. 1.45, National Institutes of Health, Bethesda, MD, USA), as shown in Figure 1 (18).

a. Percentage of peri-implant BA. Areas occupied by bone around the implant and between the threads were subtracted from the total ROI along the entire length of the implant (Fig. 1A).

b. Percentage of BIC. The amount of bone contact was defined as the percentage of the length of the implant where there was direct $\mathrm{BIC}$, without intervening soft-tissue layers. Measurements were performed along the entire length of the implant (Fig. 1B).

\section{Statistical Analysis}

All measurements were statistically evaluated using GraphPad Prism, version 5.0 (GraphPad Software Inc., La Jolla, CA, USA). Mean values and standard deviations (SDs) were calculated. The method of D'Agostino and Pearson was used to confirm that the data followed Gaussian distributions. Two-way analysis of variance (ANOVA) with Tukey's post hoc test was used to examine differences between different experimental time points for the same group. Additionally, Student's t tests were performed to determine differences between the two different groups (TN and TA) at the same experimental time point. Differences were considered statistically significant at $p<0.05$.

\section{Results}

\section{General Observations}

All animals remained in good health during the experimental period and did not show infection or other post-operative wound healing complications. The soft tissues around the implants did not show signs of inflammation or adverse tissue reactions after the experimental period. No implants were excluded from the study.

\section{Histologic Analysis}

Overall, the descriptive qualitative histologic analysis showed time-dependent new bone formation in both groups. At day 7, the TN and TA groups showed only a few areas of new bone formation, with drilling debris on the implant surface mainly in the TA group (Figs. 2A,B).

After 14 days, most of the drilling debris had been resorbed. Moreover, the TN group presented a slight increase in the bone volume, with discrete regions of BIC, whereas the increase in the BA in the TA group was very perceptible (Figs. 2C,D).

At day 21, the TA group exhibited a greater amount of new bone than in the TN group. The TA group presented a great amount of more compact trabecular bone than at

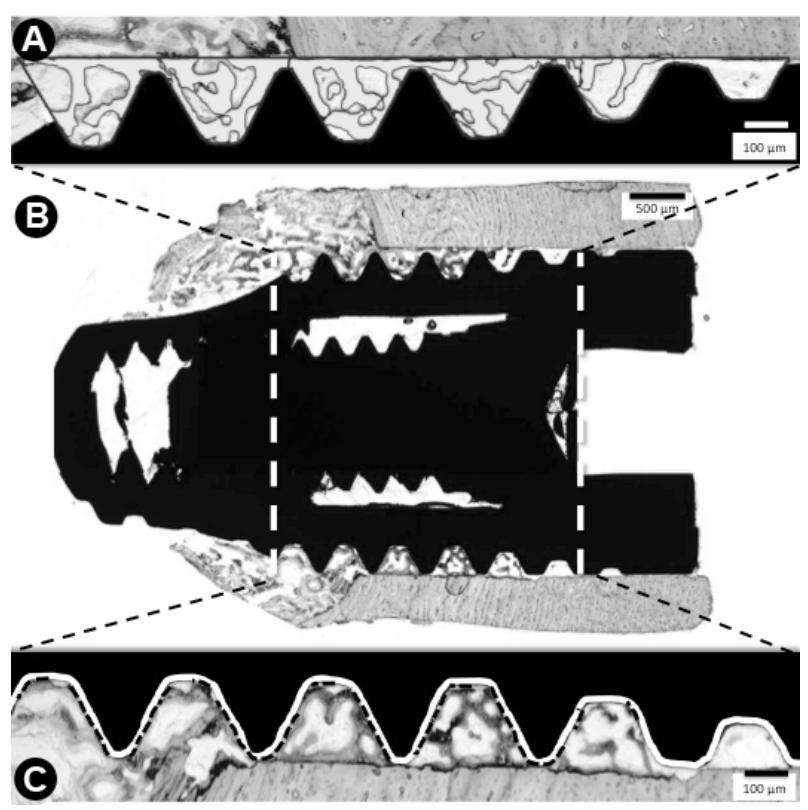

Figure 1. ROI (B) began below the first thread and finished at the last thread. (A) ROI is delimited by black-line, and the BA in this region is marked. (C) BIC is defined as tissue in contact with implant surface (dotted black-line) in ROI (white-line). 
the previous time point. Additionally, the TA group showed intimate contact of the new bone with the implant surface. This event was not observed in the TN group (Figs. 2E,F).

At 28 days, both groups showed ingrowth of new bone formation between the threads around the implants. Intimate contact between the implant and the surrounding
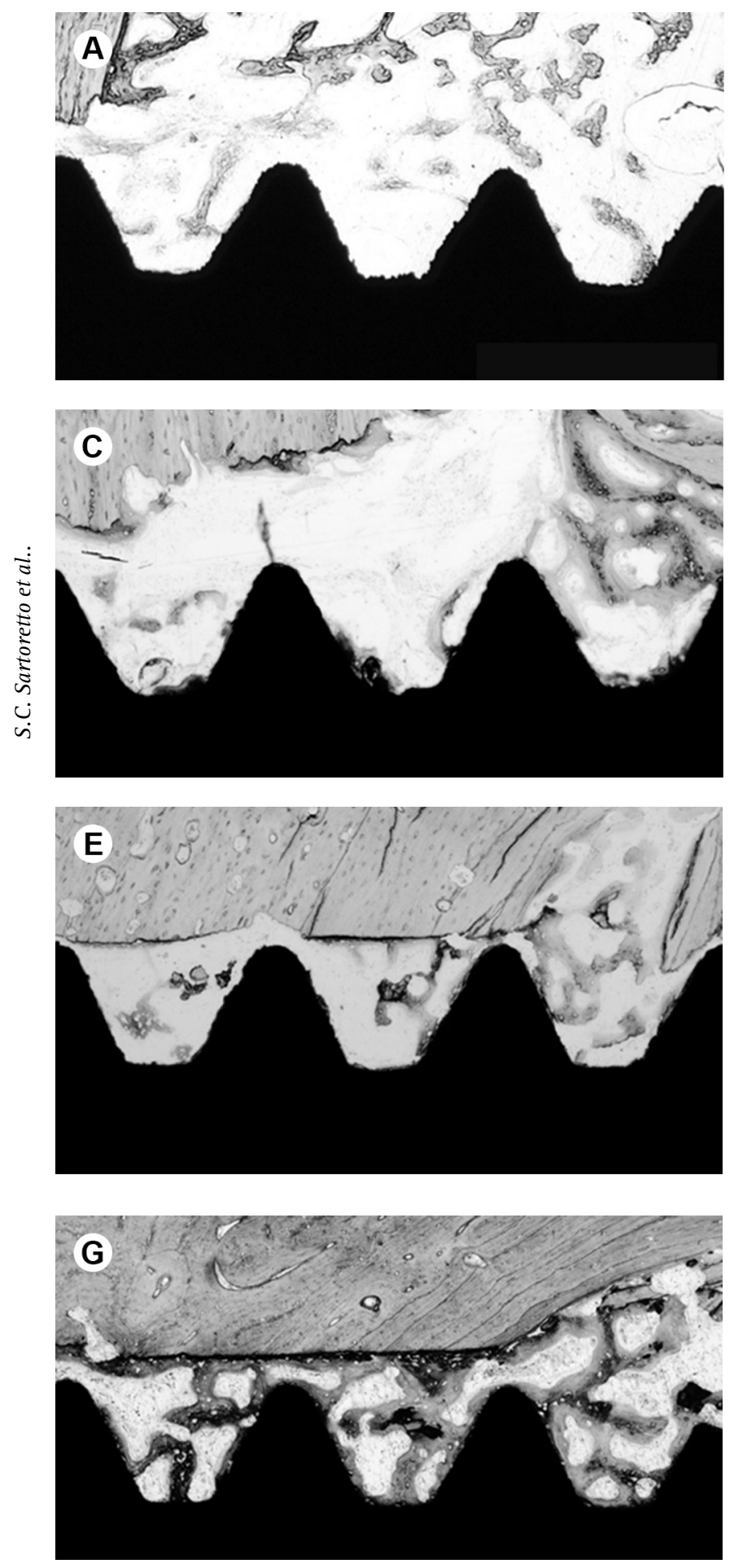

bone was observed, without a significant intervening layer of fibrous tissue. The TA group showed only a tendency toward increased new bone formation compared with the TN group (Figs. 2G,H).

\section{Histomorphometric Evaluation}
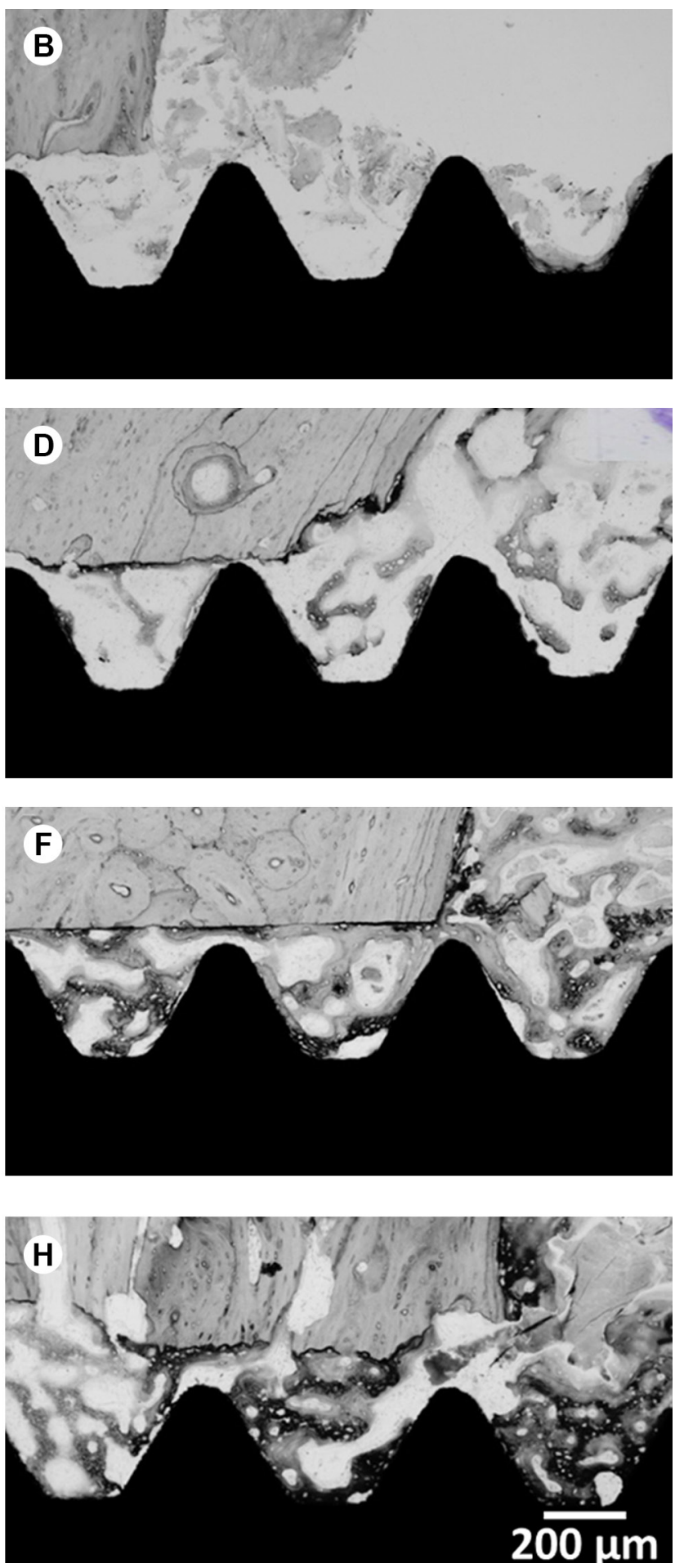

Figure 2. Photomicrographs (A), (C), (E) And (G) represent the TN group at 7, 14, 21 and 28 days, respectively. Photomicrographs (B), (D), (F) And $(\mathrm{H})$ represent the TA group at 7, 14, 21 and 28 days, respectively. Staining: toluidine-blue (magnification $\times 20)$. 
At day 7, the new BA present between the threads

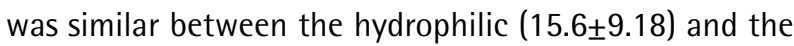
hydrophobic groups (18.56 \pm 6.77$)$. The TA group (17.8 \pm 5.2$)$ showed only a tendency toward increased BIC compared with the TN group (9.4 \pm 7.6$)$. No significant difference was observed between the two groups (Figs $3 \mathrm{~A}, \mathrm{~B}$ ).

From 7 to 14 days post-implantation, the TN group showed only a tendency toward increased BA (7 days: 18.56 ; 14 days $27 \pm 3.46$ ), whereas the TA group presented a "jump" in new BA (7 days: 15.6; 14 days: $46.6 \pm .63)$, with nearly half of the implant surface covered with new bone $(p<0.001)$. Both groups showed an increase in BIC (TN: 22.6 44.5 ; TA: $35.4 \pm 4.5$ ) compared with the BIC on day 7 . Moreover, there were significant differences between the TN and the TA groups at 14 days in terms of BA ( $p=0.003)$ and BIC ( $p=0.002$ ) (Figs. $3 A, B)$.

After 21 days, the TN group presented no difference in BA (40.2 \pm 7.36$)$ compared with the BA at 14 days post-implantation, but a significant difference in BIC $(38.2 \pm 12.1)$ was observed $(p<0.001)$. Additionally, the TA group presented increases in $\mathrm{BA}$ and $\mathrm{BIC}$ compared with the $B A$ and $B I C$ at the previous time point $(p<0.001)$. The TA group showed greater BA $(64.2 \pm 12.04)(p=0.005)$ and BIC $(60.6 \pm 4.2)(p=0.004)$ compared with the TN group (Figs. $3 A, B$ ).

At day 28 , the TN group showed a statistically significant increase in new BA (58.6 \pm 9.55$)$ and BIC $(61.4 \pm 9.4)$ compared with the $B A$ and $B I C$ at 21 days post-implantation $(p<0.001)$, whereas the TA (BA: $65.6 \pm 8.29 ; \mathrm{BIC}: 70.8 \pm 7.5$ ) group showed a stabilization of both parameters. The values of $B A$ and BIC in the TN group after 28 days were similar to the values found in the TA group 21 days post-implant placement. The BA for both surfaces reached similar values, presenting no differences between the two groups (Figs. 3A and 3B).

\section{Discussion}

The hydrophilicity of an implant surface plays decisive roles during the implant's first interactions with its host, including during the early phases of wound healing and during the cascade of events that occurs during osseointegration $(7,8,10)$. The hydrophilic surface used in the present study was created by the grit-blasting and acid-etching processed, following by storage in glass containing an isotonic solution. This process aimed to protect the pure Ti surface against contamination with organic components from the atmosphere and carbonates (19). Additionally, previous studies found that when the wettability of surface is increased, the biocompatibility is improved (20), favoring interactions between the host's biological environment and the implant surface, which contribute to activation of cellular activity (21).

The sheep model used in our study is considered to be suitable for biomedical research due to the similarities of sheep to humans regarding weight, the structure of joints, bone tissue and particularly bone regeneration $(22,23)$. Thus, sheep are an excellent model for the evaluation of dental implant systems designed for humans. Additionally, the sheep model was chosen in accordance with the guidelines of the 3Rs Program (Reduction, Refinement, Replacement), which aims not only to reduce the number of animals during experimentation but also to minimize pain and discomfort (23).

Important findings were identified among the results presented above. Time-dependent increases in BA and BIC were observed for both the hydrophilic and the hydrophobic surfaces. Additionally, our data showed a greater increase in BA in the TA group at 14 days, with $46.6 \%$ of the ROI filled with new BA, which indicated favorable osseointegration at this early point in healing. Moreover, there were
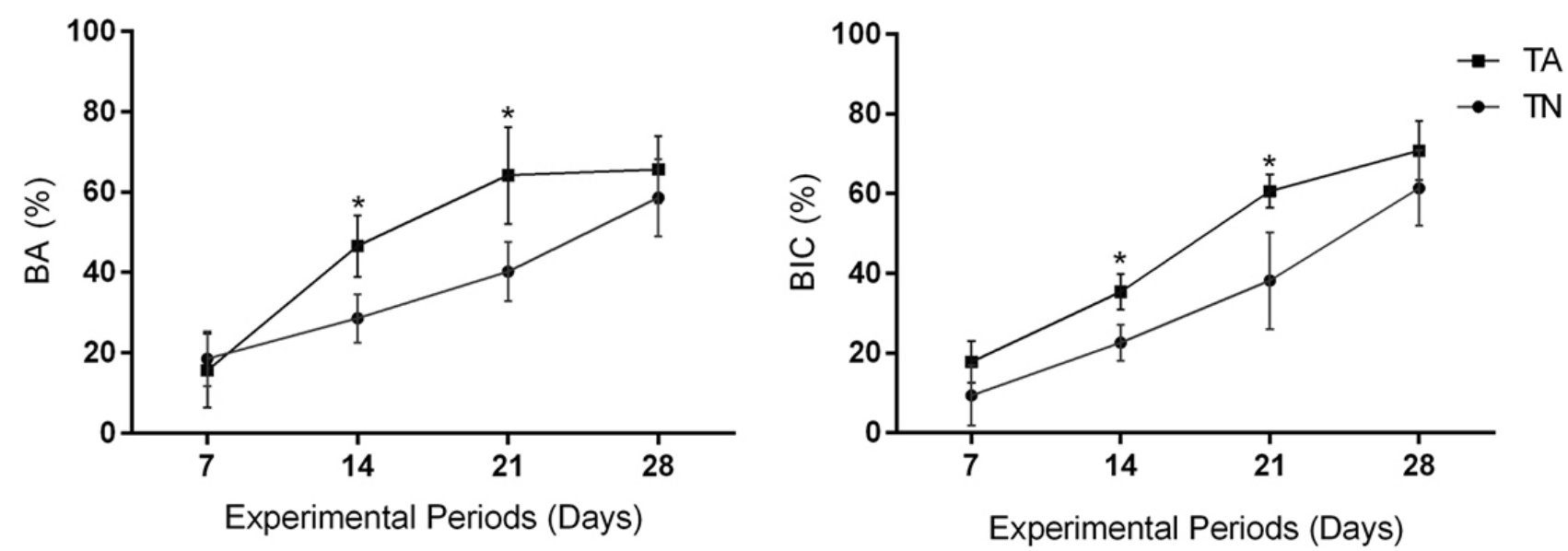

Figure 3. Amount (\%) of BA (A) and BIC (C) in groups at experimental periods. $\left({ }^{*}\right)$ represents a statistically significant difference between groups at same experimental time point. The results are shown as the mean percentage \pm SD. 
differences between the two groups in terms of the BA and $\mathrm{BIC}$ parameters after 14 days of healing. This finding is similar to that of a previous clinical trial that investigated the early steps of healing in the presence of hydrophilic surfaces and found a superior degree of osseointegration after 14 days of implantation (14). Moreover, a study using mini-pig model found great bone apposition on hydrophilic surfaces 10 and 15 days post-implant placement (6). This finding corresponds very well with the same parameters assessed in dog mandibles, which showed enhanced bone formation surrounding the hydrophilic surface of implants after 14 days of healing (3).

After 21 days of implantation, differences were also observed between the groups regarding $\mathrm{BA}$ and $\mathrm{BIC}$, and both groups showed higher values compared with those on day 14. After a healing period of 28 days, no differences between the groups were observed, and these data are supported by the literature. A previous study (3) found no differences in BA or BIC values between hydrophilic and hydrophobic surfaces after 28 days of implantation. However, Lang at al. (14) observed greater BIC for a hydrophilic surface at 28 days, but after 42 days, this difference was no longer evident. A pre-clinical study (4) analyzing bone apposition on different surfaces observed differences between hydrophilic and hydrophobic surfaces after 14 and 28 days but noted similar results between the two surfaces after 8 weeks.

The only point at which there was no time-dependent enhancement of BIC or BA was between 21 and 28 days post-implantation in the TA group. Stabilization of these parameters was found, suggesting a balance of bone remodelling.

The hydrophilic surface when compared to hydrophobic implants presents better results in in vitro studies (7) and in both preclinical $(3,4,6,15)$ and clinical studies $(14)$. In a recent pre-clinical study evaluating histologically and histomorphometrically the hydrophilic and hydrophobic implant surfaces placed in sheep tibia a significant superiority in both parameters (BA and BIC) was observed in the hydrophilic group starting at 14 days (15).

In a recent prospective randomized clinical trial the authors investigated the effect of healing period with the stability of hydrophilic implant surface at maxillary posterior area after 6 and 12 weeks. The patients also took periapical radiographs after final restoration, 6 and 12 months after restoration and final follow up period. The authors concluded that the period of 6 weeks can make the similar clinical prognosis of implants to that of healing period of 12 weeks and after 12 months all implants survived and the success rate was $97.56 \%$ (24).

A recent review article discussing the impact of dental implant surface modifications on osseointegration, report that although randomized, controlled clinical trials on hydrophilic implants are still scarce in the literature, the studies have showed better outcomes of hydrophilic implants when compare with hydrophobic surfaces (25).

On review of the available human studies (26) have found some clinical evidence to clearly state a preference for hydrophilic surface over hydrophobic implants. In a split-mouth study, hydrophilic implants were compared to hydrophobic implants with early loading protocols in irradiated oral squamous cell carcinoma patients. Onehundred-and-two implants were placed in 20 patients in both jaws. After 1-year of follow-up, there was a high survival rate (100\%) for hydrophilic group versus $96 \%$ for hydrophobic group) and low crestal bone loss $<0.4 \mathrm{~mm}$ in both groups with no significant difference (27).

This promising technology positively influences osseointegration, demonstrating intense and rapid osteogenesis around implants, as observed in our study. Our results, together with all studies cited, indicate great benefits of hydrophilic surfaces regarding wettability, accelerating early osseointegration.

The TA group showed greater bone anchorage in the early period ( 14 and 21 days) compared with the hydrophilic surface, suggesting that the hydrophilic surface contribute to the reduction in the healing period post-implant placement in sheep. Clinical trials would be relevant to address this question.

\section{Resumo}

0 objetivo deste estudo foi avaliar a osseointegração precoce de duas superficies diferentes de implantes, uma superficie tratada com jateamento e ataque ácido (TN) comparada com outra superficie com a mesma geometria e rugosidade e modificada com hidrofilicidade / molhabilidade através do condicionamento em solução isotônica de 0,9\% de cloreto de sódio (TA) através de análises histológica e histomorfométrica após a implantação em tíbia de ovelhas. Quarenta implantes dentários, divididos em dois grupos (TN e TA), foram implantados na tíbia esquerda de vinte ovelhas Santa Inês ( $n=5 /$ periodo experimental) saudáveis e esqueleticamente maduras. Após 7, 14, 21 e 28 dias pós-implantação, as amostras foram coletadas e as ovelhas foram mantidas vivas. A análise dos cortes em resina $(30 \mu \mathrm{m})$ permitiu a quantificação da área de osso (BA) e do contato osso-implante (BIC). 0 grupo TA apresentou aumento de quase $50 \%$ na BA aos 14 dias ( $p<0,001$, ANOVA - pós teste de Tukey) em comparação com 7 dias. 0 grupo TA apresentou valores maiores do que o TN para BA e BIC aos 14, 21 e 28 dias após a implantação, estabilizando a cicatrização óssea. A superfície hidrofilica TA promoveu uma osseointegração precoce aos 14 e 21 dias em relação à TN, acelerando o periodo de cicatrização óssea após a instalação dos implantes em tíbias de ovelha.

\section{References}

1. Albrektsson $\mathrm{T}$, Brånemark $\mathrm{PI}$, Hansson $\mathrm{HA}$, Lindström J. Osseointegrated titanium implants: Requirements for ensuring a long-lasting, direct bone-to-implant anchorage in man. Acta Orthop Scand 1981;2:155170.

2. Wennerberg A, Albrektsson T. Effects of titanium surface topography on bone integration: a systematic review. Clin Oral Impl Res 
2009;20:172-184.

3. Hirakawa Y, Jimbo R, Shibata Y, Watanabe I, Wennerberg A, Sawase T. Accelerated bone formation on photo-induced hydrophilic titanium implants: an experimental study in the dog mandible. Clin Oral Implants Res 2013;24:139-144.

4. Buser D, Broggini N, Wieland M, Schenk RK, Denzer AJ, Cochran DL, et al.. Enhanced bone apposition to a chemically modified SLA titanium surface. J Dent Res 2004;83:529-533.

5. Gottlow J, Barkamo S, Sennerby L. An experimental comparison of two different clinically used implant designs and surfaces. Clin Implant Dent Relat Res 2012;14:204-212.

6. Vasak C, Busenlechner D, Schwarze UY, Leitner HF, Munoz Guzon F,

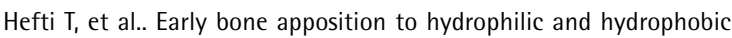
titanium implant surfaces: a histologic and histomorphometric study in minipigs. Clin Oral Impl Res 2014;25:1378-1385.

7. Wall I, Donos N, Carlqvist K, Jones F, Brett P. Modified titanium surfaces promote accelerated osteogenic differentiation of mesenchymal stromal cells in vitro. Bone 2009;45:17-26.

8. Zhao G, Schwartz Z, Wieland M, Rupp F, Geis-Gerstorfer J, Cochran DL, et al.. High surface energy enhances cell response to titanium substrate microstructure. J Biomed Mater Res A 2005;74:49-58.

9. Hong J, Kurt S, Thor A. A hydrophilic dental implant surface exhibit thrombogenic properties in vitro. Clin Implant Dent Relat Res 2013;15:105-112.

10. Hamlet $\mathrm{S}$, Alfarsi M, George R, Ivanovski S. The effect of hydrophilic titanium surface modification on macrophage inflammatory cytokine gene expression. Clin Oral Implants Res 2012;23:584-590.

11. Schwarz F, Jung RE, Fienitz T, Wieland M, Becker J, Sager M. Impact of guided bone regeneration and defect dimension on wound healing at chemically modified hydrophilic titanium implant surfaces: an experimental study in dogs. J Clin Periodontol 2010;37:474-485

12. Eriksson C, Nygren $H$, Ohlson K. Implantation of hydrophilic and hydrophobic titanium discs in rat tibia: cellular reactions on the surfaces during the first 3 weeks in bone. Biomaterials 2004;25:47594766.

13. Donos N, Hamlet S, Lang NP, Salvi GE, Huynh-Ba G, Bosshardt DD, et al.. Gene expression profile of osseointegration of a hydrophilic compared with a hydrophobic microrough implant surface. Clin Oral Impl Res 2011;22:365-372.

14. Lang NP, Salvi GE, Huynh-Ba G, Ivanovski S, Donos N, Bosshardt DD. Early osseointegration to hydrophilic and hydrophobic implant surfaces in humans. Clin Oral Implants Res 2011;22:349-356.

15. Sartoretto SC, Alves ATNN, Zarranz L, Jorge MZ, Granjeiro JM, CalasansMaia MD. Hydrophilic surface of Ti6AI4V-ELI alloy improves the early bone apposition of sheep tibia. Clin Oral Implants Res 2016 Doi: $10.1111 /$ clr.12894.

16. Sartoretto SC, Uzeda MJ, Miguel FB, Nascimento JR, Ascoli F, CalasansMaia MD. Sheep as an experimental model for biomaterial implant evaluation. Acta Ortop Bras 2016;24:262-266.

17. Kilkenny C, Browne W, Cuthill IC, Emerson M, Altman DG. NC3Rs Reporting Guidelines Working Group. Animal Research: reporting in vivo experiments: the ARRIVE guidelines. Brit J Pharmaco 2010;588:2519-2521.

18. Alharbi HM, Babay N, Alzoman H, Basudan S, Anil S, Jansen JA. Bone morphology changes around two types of bone-level implants installed in fresh extraction sockets - a histomorphometric study in Beagle dogs. Clin Oral Impl Res 2014;2:1-7.

19. Steinemann SG. Titanium - the material of choice? Periodontol 2000 1998;17:7-21.

20. Das K, Bose S, Bandyopadhyay A. Surface modifications and cellmaterials interactions with anodized Ti. ActaBiomater 2007;3:573-585.

21. Gentile P, Chiono V, Tonda-Turo C, Ferreira AM, Ciardelli G. Polymeric membranes for guided bone regeneration. Biotechnol J 2011;6:11871197.

22. Gustaldi FPS, Yoo D, Marin C, Jimbo R, Tovar N, Zanetta-Barbosa D, et al.. Plasma tratment maintains surface energy of the implant surface and enhances osseointegration. Int J Biomater 2013;13:1-6.

23. NC3Rs Reporting Guidelines Working Group. Animal Reseach: Reporting in vivo experiments: the ARRIVE guidelines. J Physiol 2010; 588:2519-2521.

24. Kim SB, Yun PY, Kim SY, Yi YJ, Kim JY, Kim YK. Prospective randomized clinical trial of hydrophilic tapered implant placement at maxillary posterior area: 6 weeks and 12 weeks loading. J Adv Prosthodont 2016;8:396-403.

25. Smeets R, Stadlinger B, Schwarz F, Beck-Broichsitter B, Jung O, Precht C, Kloss $F$, et al.. Implact of dental implant surface modification on osseointegration. Biomed Res Int 2016 doi: 10.1155/2016/6285620.

26. Wennerberg A, Galli S, Albrektsson T. Current knowledge about the hydrophilic and nanostructured SLActive surface. Clin Cosmet Investig Dentist 2011;3:59-67.

27. Heberer S, Kilic S, Hossamo J, Raguse JD, Nelson K. Rehabilitation of irradiated patients with modified and conventional sandblasted acidetched implants: preliminary results of a split-mouth study. Clin Oral Implants Res 2011;22:546-551.

Received February 23, 2017 Accepted June 26, 2017 